22 June - 5 July 2015

Conference Proceedings Paper - Remote Sensing

\title{
Airborne LiDAR and Hyperspectral Data to Support the Seismic Vulnerability of Urban Environments
}

\author{
Antonio Costanzo ${ }^{1 *}$, Antonio Montuori ${ }^{1, \dagger}$, Juan Pablo Silva ${ }^{2, \dagger}$, Malvina Silvestri ${ }^{3, \dagger}$, Massimo \\ Musacchio $^{3, \dagger}$, Maria Fabrizia Buongiorno ${ }^{3, \dagger}$, Salvatore Stramondo ${ }^{3, \dagger}$ \\ 1 Istituto Nazionale di Geofisica e Vulcanologia, Centro Nazionale Terremoti, Via P. Bucci Cubo \\ 30c, 87036 Rende (CS), Italy; E-Mail: antonio.montuori@ingv.it (A.M.) \\ 2 Comisión Nacional de Actividades Espaciales (CONAE), Agencia de Recaudación de la Provincia \\ de Buenos Aires (ARBA), Argentina; E-Mails: jpsilva@arba.gov.ar (J.P.S.) \\ 3 Istituto Nazionale di Geofisica e Vulcanologia, Centro Nazionale Terremoti, Via di Vigna Murata, \\ 605 - 00143 Roma, Italy; E-Mails:malvina.silvestri@ingv.it (M.S.); massimo.musacchio@ingv.it \\ (M.M.); fabrizia.buongiorno@ingv.it (M.F.B.); salvatore.stramondo@ingv.it (S.S.)
}

$\dagger$ These authors contributed equally to this work.

* Istituto Nazionale di Geofisica e Vulcanologia, Centro Nazionale Terremoti, Via P. Bucci, Cubo 30C, 87036 Rende (CS), Italy; E-Mail: antonio.costanzo@ingv.it (A.C.); Tel.: +39-0984-496068.

Published: 25 June 2015

\begin{abstract}
The knowledge of topographic features and building properties is a relevant operational task for evaluating the seismic vulnerability of urban environments as well as for managing post crisis events, restoration activities and supporting search \& rescue operations. Within such a framework, airborne remote sensing tools, such as LiDAR and Hyperspectral sensors, have demonstrated to be powerful instruments, whose jointly use can provide meaningful parameters to describe both topographic settings and buildings properties. Based on this rationale, in this study, the operational benefits obtained by combining airborne LiDAR and Hyperspectral measurements are provided to support the seismic vulnerability assessment of urban seismic areas. The terrain and surface digital models are gathered by using LiDAR data, while roads and roof materials information are provided through the supervised classification of Hyperspectral images. The objective is to combine these products within a Geographic Information System (GIS) platform to provide value-added thematic maps that can be used to support the seismic vulnerability analysis of urban environments. Meaningful experimental results are gathered for the city of Cosenza (Italy) in terms of topographic, building and road assessment maps. They allow
\end{abstract}


demonstrating the benefits of the proposed approach for both seismic assessment and risk mitigation purposes.

Keywords: Hyperspectral images; LiDAR; Historical heritages; Seismic Vulnerability

\section{Introduction}

The seismic vulnerability analysis of urban environments is an operational issue that concerns the comprehensive knowledge of both building structural features and soils geophysical parameters, especially when considering areas that are prone to natural and/or anthropogenic disasters (e.g. earthquakes, landslides, fires, flooding and so on). The seismic vulnerability defines the inherent weakness of both urban environment and resources, which are prone to be damaged by earthquakes and hence susceptible to seismic risk, taking into account the time-span and the spatial domain where hazards occur. During the last years, the importance of urban seismic vulnerability concept has increased due to the complexities of urban environments as well as the growth in both urbanization and population processes [1]. The growing costs related to major disasters, together with the increasing risk for both environmental ecosystem and human life, have stimulated an increasing demand for timely and spatially effective strategies to manage the damaging effects of seismic-related hazards [2-3]. Along with this rationale, a multi-disciplinary approach should be suitable to provide both an effective assessment of urban resources and synthetic parameters for managing pre and post crisis events, restoration activities and search $\&$ rescue operations.

Within such a framework, it is worth noting that the seismic vulnerability assessment is an illstructured problem, i.e. it has multiple solutions and contains uncertainties about the concepts, the rules, and the principles involved to reach expected meaningful solutions [4]. Therefore, such a problem lacks a single solution algorithm and even when the solution is provided, the latter can be considered inappropriate depending on several factors, e.g. the field of application, the vulnerability concept and the methodological path followed to provide a reliable solution [5]. In fact, the development of effective seismic vulnerability assessment methodologies must take into account several variables, processes and phenomena, such as the linkage between socio-economic or demographic characteristics and the hazard degrees defined by specific social theory, the relationship between topographic features and structural element dynamics, as well as the assessment of damage estimates from previous disasters, which are often not reliable enough to capture the differential patterns of vulnerability [6]. In addition to this, some limitations must be considered for the development of a reliable vulnerability assessment procedure, such as: (a) deficiencies of widelyavailable and cost-effective commercial software in modelling socio-economic, historic, structural and topographic data; (b) the lack of both appropriate large data volumes and reliable methods able to describe the vulnerability phenomenon under investigation; (c) the difficulty to both effectively meet the user requirements and provide consistent results (i.e. indexes, thematic maps or more generally synthetic descriptors of the seismic vulnerability) easily understandable and manageable by different stakeholders (e.g. end-users, technical personnel, decision makers, institutions, etc.) [6]. As a matter of 
fact, identifying an appropriate design structure for the assessment procedure represents a key step in the seismic vulnerability analysis of both urban environments and resources.

Along with this rationale, the formulation and the understanding of operational seismic vulnerability assessment procedures could be possible in a holistic manner by considering several time dependent variables related to the vulnerability concepts (e.g. economical, political, physical and social ones) at different spatial scales (e.g. local, regional, national and international levels) [7]. In this regard, the integration of urban environment information (e.g. ground conditions, buildings, infrastructure and services) and the knowledge of both time dependent urban changing conditions (either in absence or in place of earthquakes) and site seismic effects in terms of human losses, fatalities and destructions, could be suitable to provide effective risk reduction strategies for urban environments [8]. Within such a framework, airborne remote sensing and advanced geographic information system (GIS) tools represent key factors that are able to supply effective contribution to specific monitoring needs for seismic vulnerability mitigation purposes.

On the one hand, airborne remote sensing can offer different technological solutions in terms of sensors (i.e. active and passive tools operating in specific ranges of the electromagnetic spectrum) and techniques (both in temporal and spectral domains), which can adequately meet user requirements based on the considered vulnerability concept and the corresponding field of application. Moreover, the use of airborne platforms allows gathering several benefits for environmental monitoring and vulnerability assessment purposes in terms of very high spatial resolution (less than meter scales), operability (real-time, near-real-time and offline measurements), revisit-time (daily scales), accuracy (up to sub-meter scales), the easily schedule changes to face location and weathering problems (e.g. clouds, sunlight illumination), the sensor maintenance, repairing and configuration as well as the freeboundaries flight paths (except for political ones). However, some limitations must be considered when using airborne platforms, such as the weather conditions, the high cost per unit area of ground coverage, the narrowed field of view to the sensor provided by low altitude flights, the turnaround time and the platform stability. In this context, Light Detection And Ranging (LiDAR) and Hyperspectral sensors have demonstrated to be powerful active and passive remote sensing tools, respectively, whose jointly use allow providing meaningful parameters for the 3-dimensional (3D) analysis of urbanized areas in terms of geometrical, spectral and structural features [9-10]. In fact, both the topographic settings (e.g. terrain height and slope, land cover \& land use mapping) and the buildings properties (e.g. building height, typology, and coverage, density and distribution) of selected test areas can be reconstructed through the value-added processing of LiDAR and Optical remote sensing data.

On the other hand, GIS platforms represent an advanced key software solution to manage remote sensing products, offering several benefits in terms of: (i) time-consuming and spatial processing analysis; (ii) the collection, the management and the integration of huge amount of heterogeneous data represented as overlapping / interconnected layers; (iii) the visual spatial information through userfriendly interfaces; (iv) the powerful spatial and temporal multi-criteria approaches to tackle vulnerability assessment analysis [11-12]. As a results, all the products provided through the jointly use of remotely sensed measurements and GIS tools could be very useful for evaluating the exposure and susceptibility levels of complex urbanized environments, thus supporting structural building analysis, protection measures, urban planning activities, evacuation plans, search $\&$ rescue operations. 
Based on this rationale, in this study, the operational benefits obtained by combining airborne LiDAR and Hyperspectral measurements within a GIS platform are demonstrated to support the seismic vulnerability assessment of urban seismic areas. In detail, airborne LiDAR measurements are used to provide the digital elevation models as well as the geometrical characteristics of the buildings in the observed area. Conversely, airborne Hyperspectral measurements are used to analyze the spectral information content of an urban area through supervised classification algorithms. The products provided by LiDAR and Hyperspectral image processing analysis are then combined within a GIS platform to evaluate the intrinsic properties of buildings (e.g. perimeter, area, height and type of roofs) and roads (e.g. width and position with respect to the buildings) together with the topographic features of the surrounding area (e.g. morphology and slope). The objective of the proposed approach is providing synthetic parameters and thematic maps useful for supporting seismic vulnerability assessment and mitigation methodologies, such as: (i) the identification of steep slope areas, (ii) the analysis of building roof typology for supporting the evaluation of structural load conditions, (iii) the detection of critical structures (e.g. asbestos roofs), (iv) the identification of primary roads (in terms of escape or access routes) for supporting search and rescue operations, (v) the analysis of main road conditions after building collapses. Meaningful experimental results are gathered for the historical centre of Cosenza city (Italy), which allow demonstrating the benefits of the proposed approach for both seismic assessment and mitigation purposes.

The paper is organized as follows. In Section 2, the test area is presented. In Section 3, the airborne remote sensing techniques and sensors used in this study-work are described separately. In Section 4 the methodology, that is proposed to integrate active and passive remotely sensed measurements for supporting seismic vulnerability assessment analysis, is presented. In Section 5, some meaningful experimental results are provided and discussed for the case study of Cosenza city in Calabria Region (Italy). Finally some thoughtful conclusions are drawn in Section 6.

\section{Case study}

The case study of the proposed work is the urban area of Cosenza city (South Italy), which is one of the most important municipalities within Calabria Region with a total population of 70000 people and a density of $1800 / \mathrm{km}^{2}$. The Cosenza city is the administrative centre of the homonymous Province, that includes a great number of municipalities (about 155) and occupies the entire central and northern part of the Region. From the morphological viewpoint, the Cosenza urban area is located in the Crati river valley surrounded by the mountain landscape of Sila Plateau and the Massif of Pollino, which represent interesting case studies for the environmental monitoring analysis. From the infrastructural viewpoint, the whole area comprises a great number of mobility and transport facilities as witnessed by the main junctions of the Calabria road systems (e.g. the motorway A3 Salerno-Reggio Calabria) as well as the several facilities connecting the city centre to the other Provinces of Calabria Region. Moreover, the close presence of the Calabria University (UniCal) with about 33,000 students and 2,800 university staff members, together with the several architectural and structural renovations of the historical city centre due to earthquake damages, make the whole area an interesting test case to be studied for structural and environmental monitoring purposes. In addition to these features, the Province of Cosenza is very important from geological viewpoints, since the presence of a complex 
and fragile territory, characterized by several active faults, make it prone to hydrogeological disasters (e.g. landslides) and seismic events, as witnessed by historical earthquakes recorded in Calabria on 1638, 1870 and 1905. As a result, the city of Cosenza represents an interesting test case to be studied for the risk mitigation of seismic urban areas.

Within such a framework, the proposed study-work aims at assessing the topographic amplification and the building structural features of the Cosenza urban area, which can be used for in deep seismic vulnerability assessment analyses. The research activity and the results presented in this study-work matches the project objectives of Programma Operativo Nazionale (PON) MASSIMO, namely Monitoraggio in Area Sismica di SIstemi MOnumentali. The scope of this project is the development of a multi-sensors (i.e. in situ measurements, ground-based, airborne and space-borne platforms) and multi-disciplinary (i.e. environmental and infrastructural analysis) investigation methodology for the multi-temporal and the multi-spatial monitoring of cultural heritages in response to seismic stress.

\section{Sensors and survey techniques}

In this section, it is provided the description of the physical principles, that lie at the basis of the proposed techniques (i.e. active LiDAR and passive Optical remote sensing), together with the technical specifications of each sensor used in this study-work.

\subsection{Airborne LIDAR}

Airborne LiDAR is a powerful remote sensing technology, which is widely used in literature either for directly 3D measuring elevation of Earth's surface and objects or for developing digital terrain model (DTM) and digital surface model (DSM) of observed scenarios, with high vertical and temporal accuracies [13]. It uses a laser scanner, which transmits up to 400,000 pulses of light per second and records the time delay between a light pulse transmission and reception to calculate elevation values of surface targets. The latter are integrated with information from the aircraft's Global Positioning System (GPS) and orientation (pitch, roll, and yaw) data from inertial measurement technology, to produce point cloud data representing the elevation of observed targets, each one recorded with precise position, elevation and other attribute values [13].

In this study-work, the airborne LiDAR survey is carried out by RIEGL LMS-Q680i sensor, which is able to interface with the GNSS/INS NOVATEL SPAN /SE receiver, providing continuous position and altitude of surface targets even during periods when satellite signals are blocked. For each received pulse, the sensor provides information of both position and radiometric intensity.

The airborne LiDAR data have been firstly pre-processed through the dedicated RIEGLC software package to extract the unclassified point clouds from received light pulses. Therefore, following the removal of point cloud outliers (both low- and high-altitude points), the point-cloud classification has been performed by Terrascan $\odot$ software package to distinguish vegetation, buildings, ground and model key points. In Figure 1 it is provided the 3D LiDAR-based point clouds of the Cosenza urban area, referred to the classification schemes defined by American Society for Photogrammetry and Remote Sensing (ASPRS) for the data category. The classification map, projected over the 3D topographic profile of the case study, allows identifying and detecting the vegetated areas against the urbanized features of the Cosenza city (see green and orange point clouds, respectively, in Figure 1). 
Figure 1. Classification LiDAR-based point clouds of the Cosenza urban area

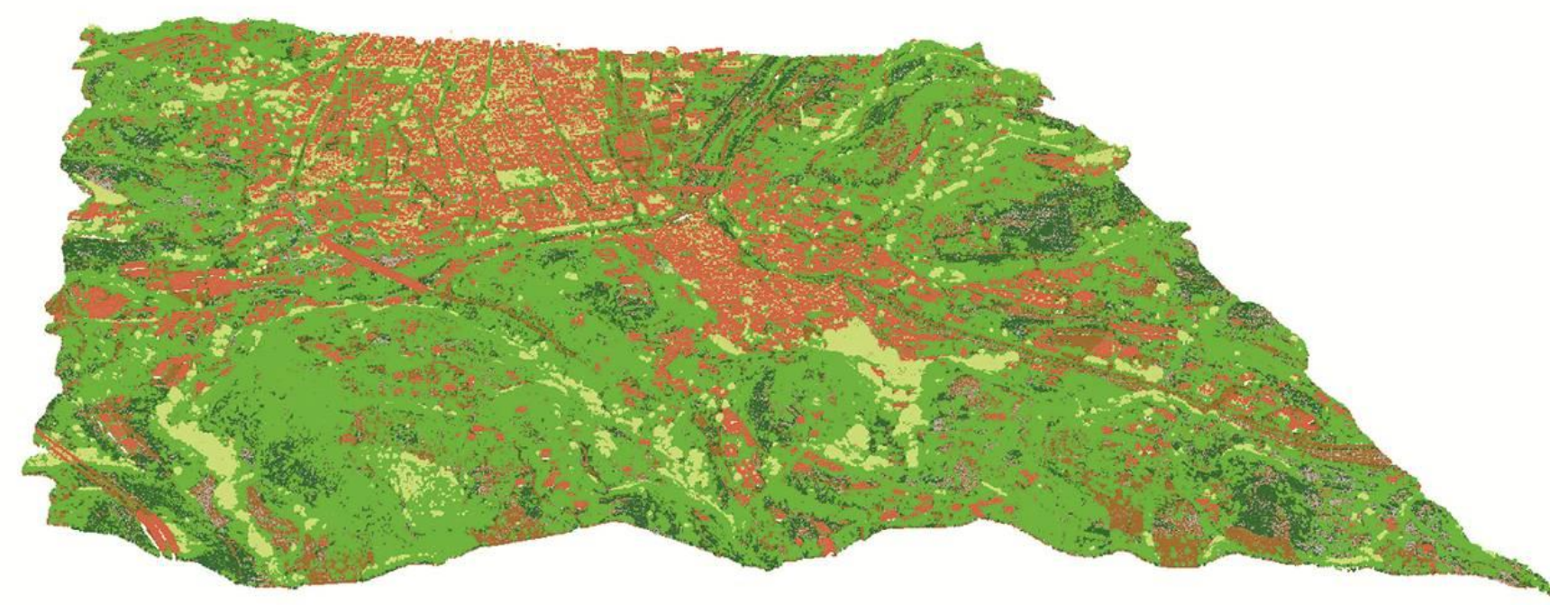

\subsection{Optical remote sensing}

Optical remote sensing is a powerful passive techniques, which makes use of visible, near infrared and short-wave infrared sensors to form images of the earth's surface by detecting the solar radiation reflected from targets on the ground [14]. Different materials reflect and absorb differently the sunlight illumination at different wavelengths and therefore they can be differentiated by their spectral reflectance signatures in the remotely sensed images. Optical remote sensing systems can be classified into different types (i.e. Panchromatic, Multispectral, Superspectral and Hyperspectral ones), depending on the number of spectral bands used in the imaging process (i.e. single, multi, tenths and hundred spectral bands, respectively) [14]. The greater is the number of spectral bands, the narrower are the wavelength bandwidths and the finer are the spectral characteristics of the targets captured by the sensor, thus enabling a better characterization and identification of targets. As a result, notwithstanding the main limitations of optical remote sensing systems related to the solar illumination and the atmospheric conditions, such systems can offer different benefits for imaging the spectral properties of observed scenarios from gray-scale to colour (true, false and natural) composite images, with the potential to reveal the underlying phenomenology beyond the spectral characteristics of the targets. The technological advances of optical remote sensing sensors over recent decades have enabled availability of large spatial coverage (up to tenths kilometres scales), high spatial (up to submeter scale), spectral (up to hundred number of bands) and temporal (up to daily revisit-time) resolution imagery to the remote sensing analyst [14-16]. These advances have created unique challenges for researchers in the remote sensing community working on algorithms for the representation, the exploitation and the analysis of such data, making them suitable for environmental applications, such as land cover \& use, change detection and monitoring analysis of urban environments, especially for risk mitigation purposes [15-16].

Within such a framework, airborne Hyperspectral imagery represents a valuable source to extract detailed information about earth surface phenomena and objects through the analysis of their spectral features. In addition to the above-mentioned benefits provided by using airborne platforms, 
Hyperspectral sensors are characterized by a very high spectral resolution that usually results in hundreds of narrow spectral channels, which allow gathering a better characterization of targets without any prior knowledge of observed areas [17]. However, the analysis of Hyperspectral imaging data is not a trivial task since many factors made the analysis quite complex, such as the large spatial variability of the Hyperspectral signature for each land cover class, the atmospheric effects and the band dimensionality requiring time-effective processing algorithms.

In this study work, IMSpectorV10E visible and near-infrared (VNIR) measurements, acquired by the airborne IPERGEO sensor, have been used and processed through supervised classification algorithms for the land-use and the land-cover mapping of the Cosenza urban area, to support the understanding and the formulation of vulnerability assessment procedures for seismic mitigation purposes. The system is mounted onboard of an airborne platform that flies at an altitude of about $500 \mathrm{~m}$. Referring to the VNIR Hyperspectral working range, the sensor provides the sample spectrum in 503 bands, with a nominal bandwidth of $2 \mathrm{~nm}$ covering a spectral range between 400 and $1000 \mathrm{~nm}$.

Figure 2. Sketch of a RGB Hyperspectral image, related to the Cosenza urban area.

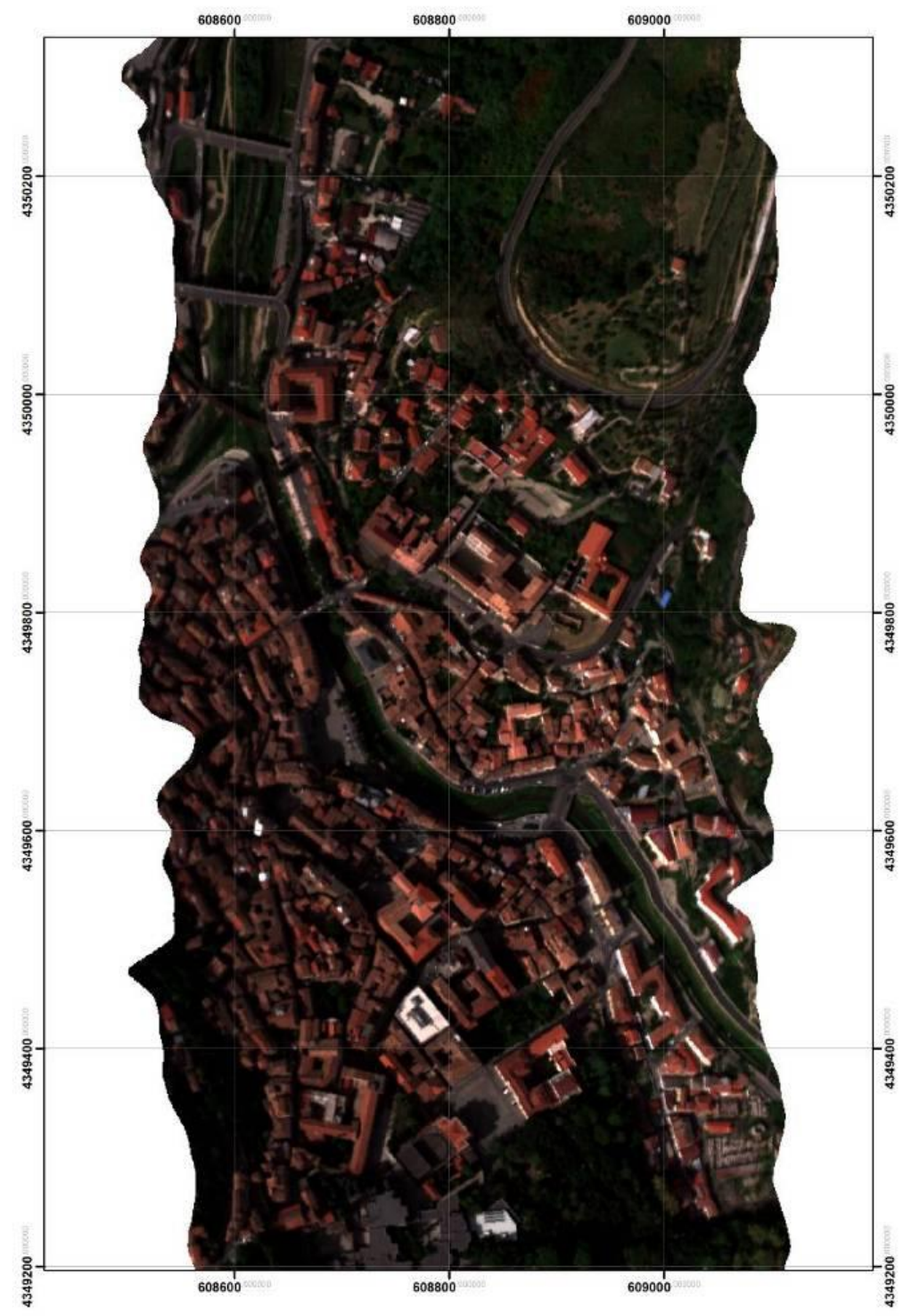


An ad-hoc pre-processing of the Hyperspectral measurements have been firstly implemented to provide geocoded reflectance measurements of targets within the observed scenario: in detail, the measurements have been radiometrically corrected, geocoded and geometrically calibrated, converted in Band Interleaved by Line (BIL) format and finally corrected for atmospheric effects. An example of the final product obtained by following the pre-processing of VNIR Hyperspectral measurements is provided in Figure 2, where a sketch of the Cosenza historic city centre is shown in the RGB colourcomposite imagery of a geocoded Hyperspectral data strip.

\section{Proposed approach}

The rationale, that lies at the base of the proposed approach, is described according to the block scheme of Figure 3, where LiDAR and Hyperspectral data are processed in a two-steps procedure to provide two different kinds of products, i.e. the intermediate and the value-added data fusion ones.

Figure 3. Block scheme of the methodology proposed to integrate airborne LiDAR and Hyperspectral measurements.

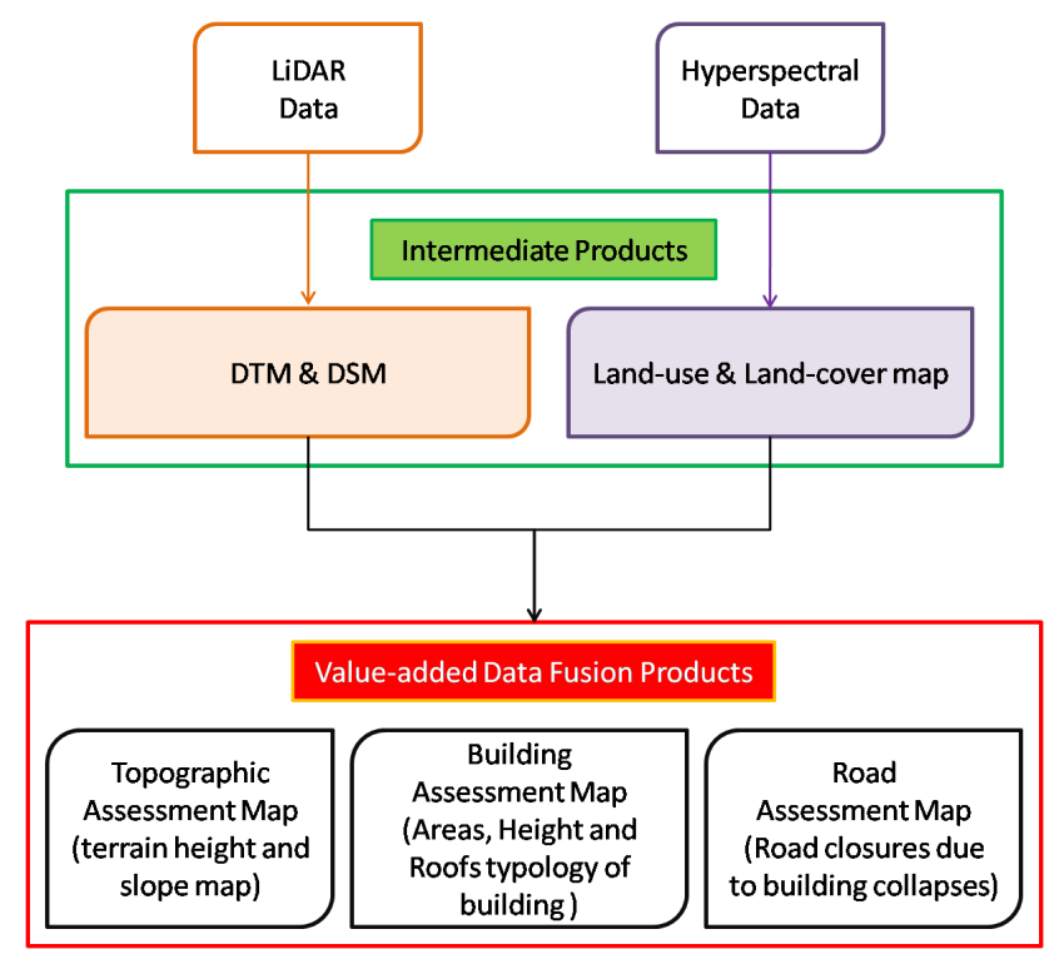

The intermediate products, which concern the first step of the proposed methodology, have been obtained by processing LiDAR and Hyperspectral measurements through classical signal techniques and spectral-based supervised classification algorithms, respectively. These products include the DTM, the DSM, the land-use and the land-cover maps of the selected case study.

The value-added data fusion products, which concern the second step of the proposed methodology, have been obtained by combining and integrating the intermediate products provided by LiDAR and Hyperspectral data within a GIS platform. The provided products include the topographic, the building and the road assessment maps of the observed test area, which allows performing environmental and infrastructural analysis for supporting seismic vulnerability assessment plans. 
In the following, the processing chains, that have been adopted to process intermediate products and then provide each value-added data fusions map for the selected test area, are described separately.

\subsection{Intermediate products: Digital models, land-cover \& land-use map}

Referring to the airborne LiDAR measurements and following their pre-processing step, these data have been processed through classical interpolation techniques to provide the DTM and DSM of the observed scenario (i.e. the Cosenza urban area) with very high spatial resolution (see Figure $4 \mathrm{a}$ and $4 \mathrm{~b}$, respectively). Based on these models, two typologies of LiDAR-based products have been extracted in GIS environment and properly shown in Figure 4c-d: (i) the topographic characterization of the urban environment; (ii) the location of the built areas over the 3D topographic profile of Cosenza urban area.

Figure 4. Intermediate products by airborne LiDAR data: DTM (a), DSM (b), map of built areas (c) and 3D view of the buildings projected on the DTM (d)
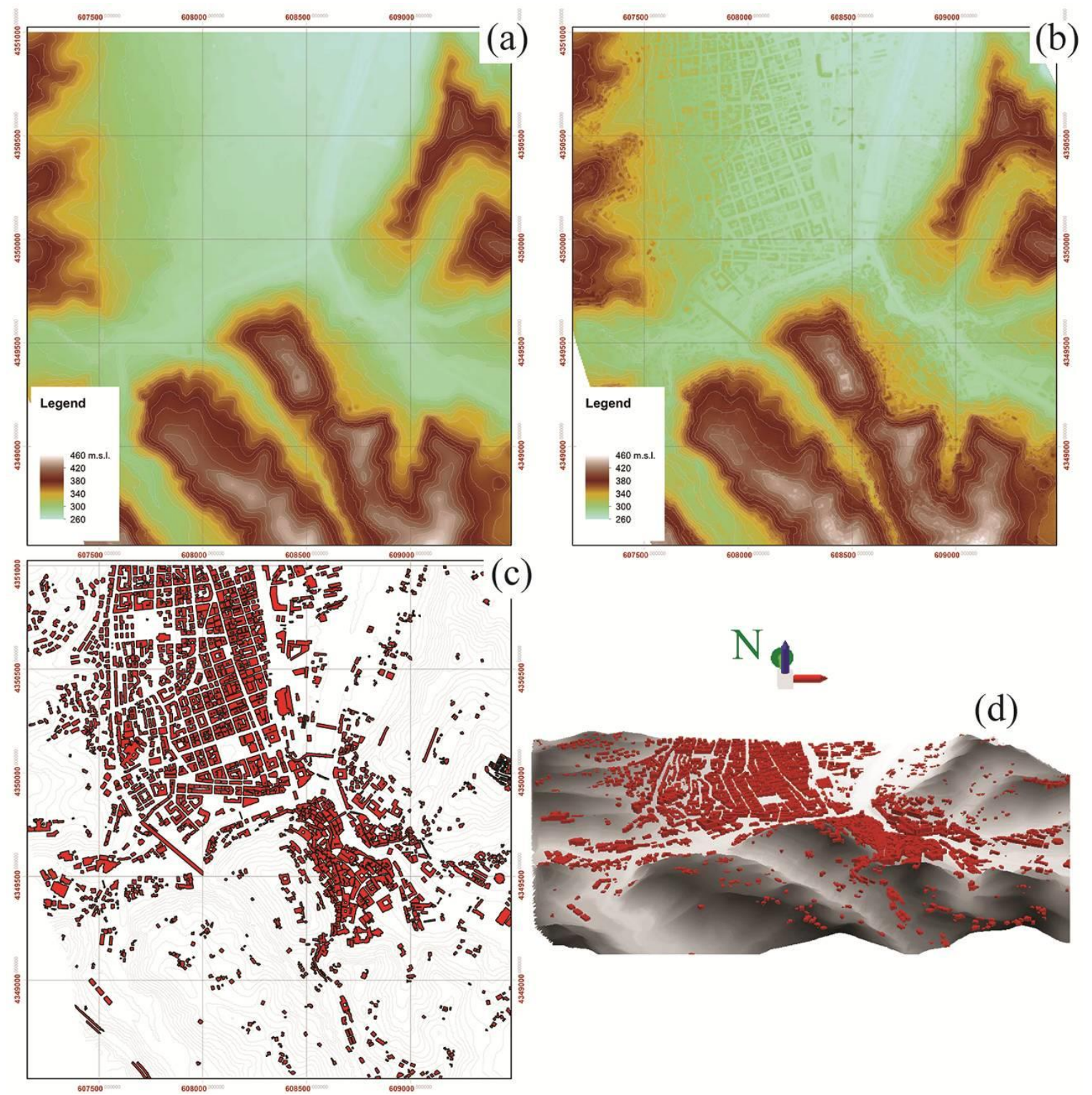

(d)
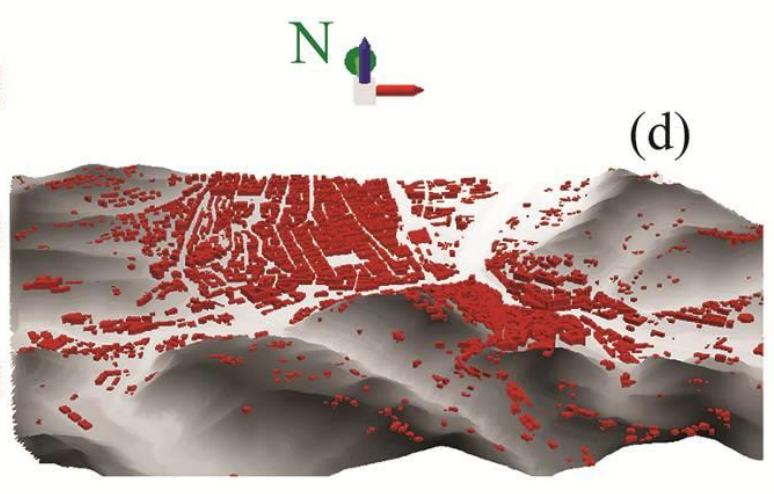

Referring to the airborne Hyperspectral data and following their pre-processing step, these images have been fully processed within the ENVI-IDLC computing environment through a supervised 
classification algorithm based on the Spectral Angle Mapper (SAM) technique [18], to provide highresolution classification maps of the observed scenario (i.e. the Cosenza urban area, see Figure 5). The algorithm allows a rapid classification by calculating the spectral similarity between the image spectrums and reference reflectance spectra. The latter can be provided either by user-defined region of interest (ROI) selected within the Hyperspectral imagery or (as in the case of this study-work) by reference spectra provided by ENVI-IDL(C) spectral libraries. SAM measures the spectral similarity by calculating the angle between the image and the reference spectra, treating them as vectors in the ndimensional feature space: the smaller angles between the two spectrums indicate high similarity and vice versa [18]. The expected output is the high-resolution description of land-use \& land-cover mapping of the observed scenario. In Figure 5, it is shown the SAM-based classification map of the Cosenza urban area, which allows identifying and detecting, in an automated and low-supervised manner, the natural environmental classes (i.e. vegetated and terrain rural areas) against the urbanized features of the area (i.e. roads and the main roof typologies of buildings, such as asphalt, brick, concrete and steel structures) with an overall accuracy of $95 \%$ and a processing time less than $5 \mathrm{~min}$. .

Figure 5. SAM-based supervised land-cover and land-use classification map of Cosenza.

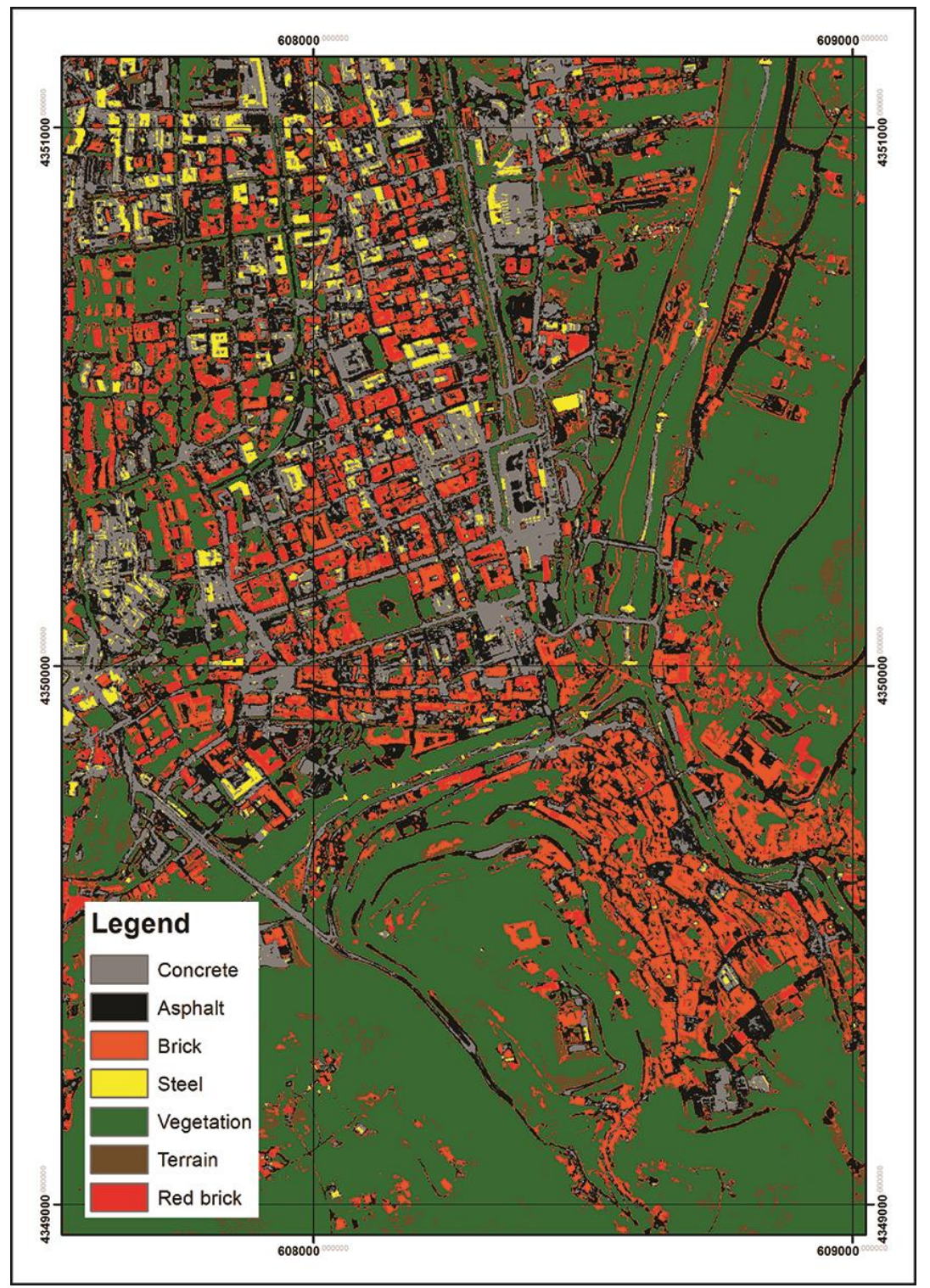




\subsection{Topographic assessment map}

An important factor that must be taken into account when evaluating and assessing the seismic vulnerability of land surface (e.g. for seismic microzonation analysis) is the topographic amplification factor, i.e. the amplification of seismic waves in presence of topographic irregularities. The latter is often advocated as one of the possible causes of damage concentration during earthquakes as well as in the (re)activation of landslides, rockslides and rock-falls during seismic ground shaking events. The topographic amplification factor depends on several variables, such as in particular the seismic source directivity effects, the land morphologies and the slopes. All these factors are relevant when referring to areas where morphological configurations of hill and steep cliffs are particularly widespread, such as in the interesting case of the Italian territory. The engineering relevance of this problem is even greater when considering that several historical towns, with precious (architectural, historic and religious) heritages, are often located at the cliff crest (e.g. [19]). In order to evaluate the topographic amplification factor, the European Technical Code (EC8) provides four type of morphologies:

- $\quad \mathrm{T} 1$ - flat surfaces, isolated slopes or reliefs with average inclination $\beta \leq 15^{\circ}$

- $\mathrm{T} 2$ - Slopes with average inclination $\beta>15^{\circ}$

- T3 - Reliefs with ridge top width much smaller than the base, and average inclination $15^{\circ} \leq \beta \leq 30^{\circ}$

- $\quad \mathrm{T} 4$ - Reliefs with ridge top width much smaller than the base, and average inclination $\beta>30^{\circ}$

Within such a framework, a topographic analysis of urban areas is here proposed, where the DTM intermediate product provided by airborne LiDAR data processing has been used with the maximum and the average slope maps of the observed scenario, together with a modified landform classification based on the one proposed by Weiss [20]. A specific tool has been developed in GIS environment based on the Topographic Position Index (TPI), which is defined as the difference between the elevation at each surface point and the average elevation of the surrounding area within a predefined radius. Positive TPI values indicate that the central point is located higher than its average surroundings, while negative values indicate a lower position with respect to the surrounding average. Moreover, the range of TPI values depends on both elevation differences and the selected reference radius [21]. In fact, large radius values mainly reveal major landscape units, while smaller ones highlight smaller features, such as minor valleys and ridges. According to this rationale, which is based both on morphology and slope analyses, each pixel of the topographic map has been classified according to the EC8 rules.

\subsection{Building assessment maps}

To outline the main features of the built up area, the position, the geometry and the height of the buildings have been extracted by airborne LiDAR data for the selected case study. In particular, for either single structures or aggregate buildings located in the historical centre of Cosenza urban area, a digital model has been developed solely with the points classified as buildings, whose footprints have been detected through polygons in a vector file. For each detected building, both the average and the maximum heights have been calculated through the evaluation of the difference between DSM and DTM, and then stored in a dedicated GIS table. In this processing, all digital models have been 
obtained by interpolating surface points at a sampling rate of $1 \mathrm{~m}$ in both range and azimuth directions, in order to evaluate detailed geometry of building footprints and accurate values of corresponding heights. Afterwards, the information on the areas and the average heights of each building have been combined to estimate the relevant volumes, which can be correlated to the exposition level of built structures in case of seismic event, both with reference to the occupant people and the economic value of the structure. These building features could be further used to correlate the vibration frequencies of structures (e.g. using simplified relationships proposed by technical code or scientific studies [e.g. 22]) to the analyses of the site seismic response in order to assess the earthquake-related effects due to the double resonance phenomenon.

Following the results of the SAM-based supervised land-cover classification carried out by using Hyperspectral data, the detected buildings have been also characterized on the basis of the roofs material. This additional information is very important to assess the presence of dangerous materials (e.g. asbestos) in the case of damaging due to seismic events, as well as to allow evaluating the building loads produced by coverage. In fact, with reference to the roof typology, the constructive experience in the South Italy suggests: (i) the use of shingles for roofs with high slope (generally included between $30 \%$ and 45\%), which ensure a good isolation; (ii) the use of impermeable materials, such as bituminous membranes, to cover the concrete roof with low slopes (less than 5\%) in order to reduce the infiltration phenomena of the rainwater; (iii) the use of steel panels for industrial warehouses or wide civil buildings with intermediate slopes of the coverage.

\subsection{Road assessment map}

A risk analysis has been performed in order to define a road assessment map of the selected case study, i.e. a suitable pattern of streets that will be not covered by buildings ruins in case of hazardous earthquakes. To accomplish this task, some parameters have been defined and a relevant index has been estimated.

Within such a framework, the proposed approach starts with the assumption of a building collapse ratio equal to $100 \%$, together with the evaluation of relevant parameters useful for the road assessment analysis, namely the roads width and the building heights. On the one hand, the location of roads has been derived by classifying Hyperspectral images using ITT-ENVIC software package, whilst the road width has been estimated by suitable analysis on GIS environment. On the other side, the building heights have been derived through the building assessment map of the observed area, by using and processing airborne LiDAR measurements within a GIS platform.

Referring to the most typical buildings for the Cosenza urban area and considering the heights estimated by LiDAR data, three different building classes have been defined in terms of elevation: (i) "Low buildings" with 1-3 storeys (height between 3-10m), (ii) "Medium buildings" with 4-7 storeys (height between 13-22m) and (iii) "High buildings" with 8 or more storeys (height $\geq 25 \mathrm{~m}$ ).

In Figure 6 it is shown a sketch where the distance between opposite buildings is provided together with the roads and sidewalks width. According to this scheme, it is possible to estimate the road width by using the following expression:

$$
W_{b r}=\frac{\left(W_{b b}-W_{r}\right)}{2}
$$


where $W_{b r}$ is the distance between building and road, $W_{b b}$ is the distance between opposite buildings, $W_{r}$ is the width of the road.

Based on the shape corresponding to the three defined classes, the perpendicular distance between opposite buildings $\left(W_{b b}\right)$ has been taken throughout the study area. Furthermore, the width of roads and sidewalks (where the visual detection has been possible) have been directly measured for 20 test sites; conversely, for all the remaining roads in the area, a statistic evaluation has been performed on the base of direct measurements, obtaining the following relationship:

$$
W_{r}=\frac{70 \cdot W_{b b}}{100}
$$

It seemed suitable to approximate the $W_{r}$ value in excess, in order not to generate false positives in the mapping (i.e. areas marked with low risk of blocking, when conversely they show high risk).

\section{Figura 6. Features of urban roads for their typological description against building collapse risk.}

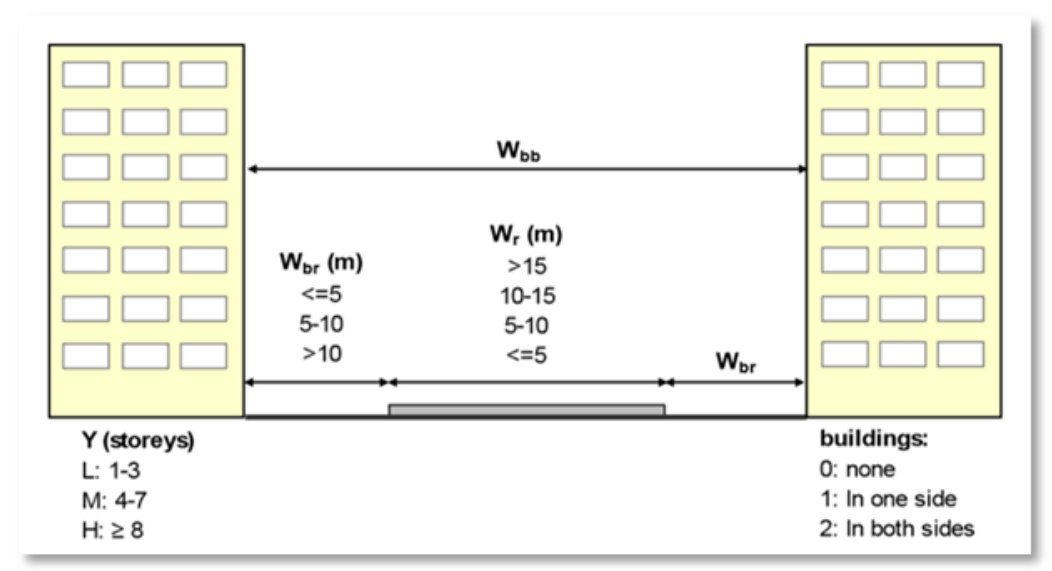

For the case study of Cosenza urban area and based on the local municipal regulations, the height of opposite buildings located along a road axis have usually shown to have similar values.. However, along the road axes either where the heights of opposite buildings are not similar or where buildings are present only on one side, the characteristic building height $(\mathrm{Y})$ has been calculated according to the following decision criteria:

i $\quad \mathrm{Y}=10 \mathrm{~m}$, for "Low buildings" on both sides;

ii $\quad \mathrm{Y}=22 \mathrm{~m}$, for "Medium buildings" on both sides;

iii $\quad \mathrm{Y}=25 \mathrm{~m}$, for "High buildings" on both sides;

iv $\mathrm{Y}$ is equal to the average height, for buildings with two different heights on both sides;

$\mathrm{v} \quad \mathrm{Y}$ is equal to the $50 \%$ of the height, for buildings only on one side of the road;

vi $\mathrm{Y}$ is the one that dominates more than $60 \%$ of the buildings, for multiple buildings with different heights in the stretch. 
To correlate the location of buildings with the road geometry, the risk index $\mathrm{D}_{\mathrm{br}}$ has been calculated as the ratio of the average distance between opposite buildings $\left(\mathrm{W}_{\mathrm{bb}}\right)$ and the road width $\left(\mathrm{W}_{\mathrm{r}}\right)$; therefore, the lower is the value of this factor, the greater is the risk of blockage in case of collapse. Assuming threshold values of the factor, three classes of risk have been defined:

i $\quad \mathrm{D}_{\mathrm{br}}<2.0$, for buildings at short distance from the road;

ii $\quad 2.0 \leq \mathrm{D}_{\mathrm{br}}<3.0$, for buildings at medium distance from the road;

iii $\quad \mathrm{D}_{\mathrm{br}} \geq 3.0$, for buildings at long distance from the road.

Applying this procedure to the urbanized area of Cosenza city, the risk factor have shown values lower than 2.0 in most of the study area, i.e. a very short distance between the buildings and the road has been observed, which would involve a high risk of blockage road. On these bases, it seemed opportune to relate the characteristic height of the buildings $(\mathrm{Y})$ with the distance from the road $\left(\mathrm{W}_{\mathrm{br}}\right)$, thus evaluating a coefficient of the roadblocks risk levels according to the following equations:

$$
D_{H R}=\frac{Y}{W_{b r}}
$$

Assuming threshold values for the closing risk of the roads, three classes have been identified on the base of eqn. (3):

i Low risk for $\mathrm{D}_{\mathrm{HR}} \leq 2.0$;

ii $\quad$ Moderate risk for $2.0 \leq \mathrm{D}_{\mathrm{HR}} \leq 4.0$;

iii High risk for $\mathrm{D}_{\mathrm{HR}}>4.0$.

\section{Experimental results}

In this section some meaningful experimental results relevant to the application of the proposed approach are presented and discussed for the case study of Cosenza city centre.

Referring to the topographic assessment analysis, the DTM has been provided by firstly interpolating airborne LiDAR data at a pixel size of 5x5m; hence it has been processed through a lowpass filter in order to reduce topographic outliers. With respect to the landform evaluation according to the modified Weiss approach, the average of the height values around each central point has been calculated using a radius of $1000 \mathrm{~m}$. Conversely, maximum and average slopes have been evaluated by considering a radius of $100 \mathrm{~m}$, in order to identify the different classes defined by the EC8. In particular, the flat earth component and the open slopes have been classified through the average slope; whereas, for the middle-upper slopes, isolated hills and crests of cliffs, the maximum slope has been taken into account for evaluating the more appropriate topographic class.

In Figure $7 \mathrm{a}$ the topographic assessment map of the Cosenza urban area is shown through the classification of the topographic amplification factor for the observed scenario. In Figure $7 \mathrm{~b}$ a 3D view of this classification analysis is projected on the local DTM, where the building positions are further 
provided. Experimental results clearly show that the $56 \%$ of the whole urban area is characterized by flat-surface topographic morphologies and hence classified as T1 class (see the green coloured areas in Figure 7). Conversely, the $42 \%$ and the $2 \%$ of the study area are characterized by low- and high-slope morphologies, respectively, and hence classified as T2 and T4 classes, respectively (see yellow and red areas in Figure 7): therefore topographic amplification factors greater than 1.2 and 1.4 should be considered, respectively. In detail, it can be observed that the historical centre of Cosenza is susceptible to not negligible phenomena of topographic amplification (see dashed box in Figure 7).

Figure 7. Land classification of the topographic amplification based on the indications proposed by technical code (EC8): 2D map (a) and 3D view (b).

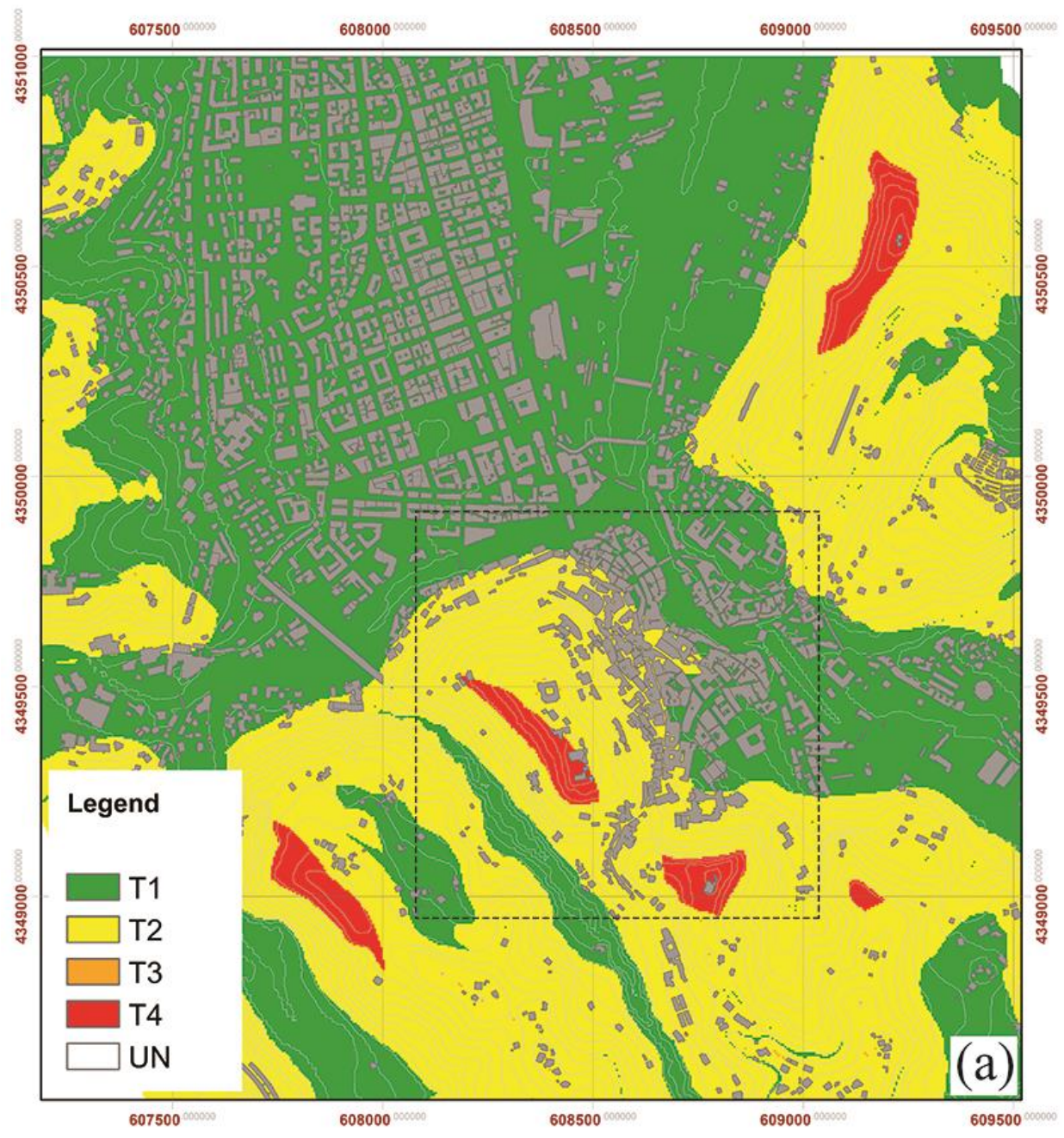

(b)

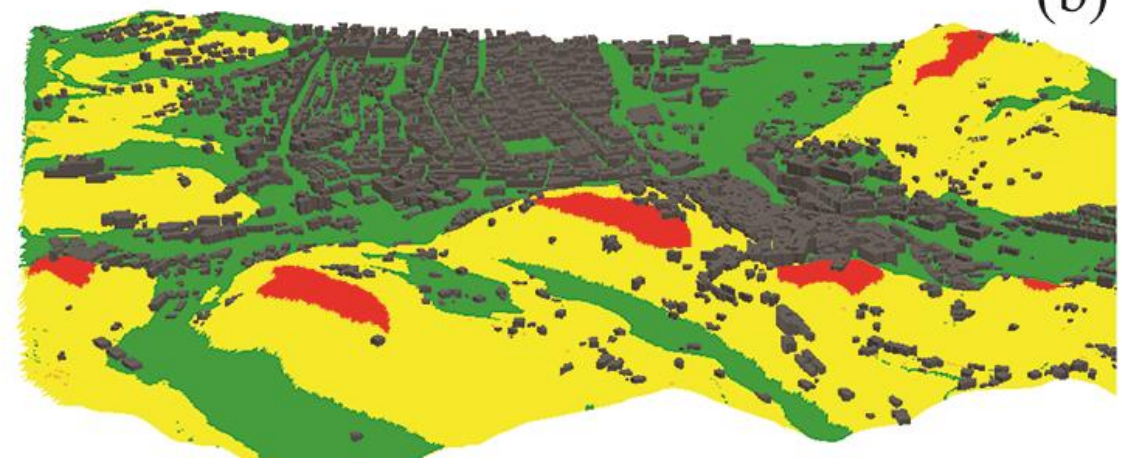


In Figure 8 the building assessment map is shown in terms of building footprints together with full and empty volumes (in cubic meter, cu.m.) occupied by each structure. Experimental results show that the most part of the buildings has volumes less than $50000 \mathrm{cu} . \mathrm{m}$. with the exception of some structures (e.g. hospital, prefecture and other buildings with host strategic functions), which are characterized by wide extension in area coverage and/or height. Referring to the historical centre of the city (see dashed box in Figure 8), a great number of buildings shows a volume greater than $20000 \mathrm{cu} . \mathrm{m}$. due to the aggregate structures and big cultural heritages of the area (i.e. theatre and religious compounds).

Figure 8. Classification of the buildings in the urban area of Cosenza based on the volumes : 2D map (upper panel) and 3D view (lower panel)
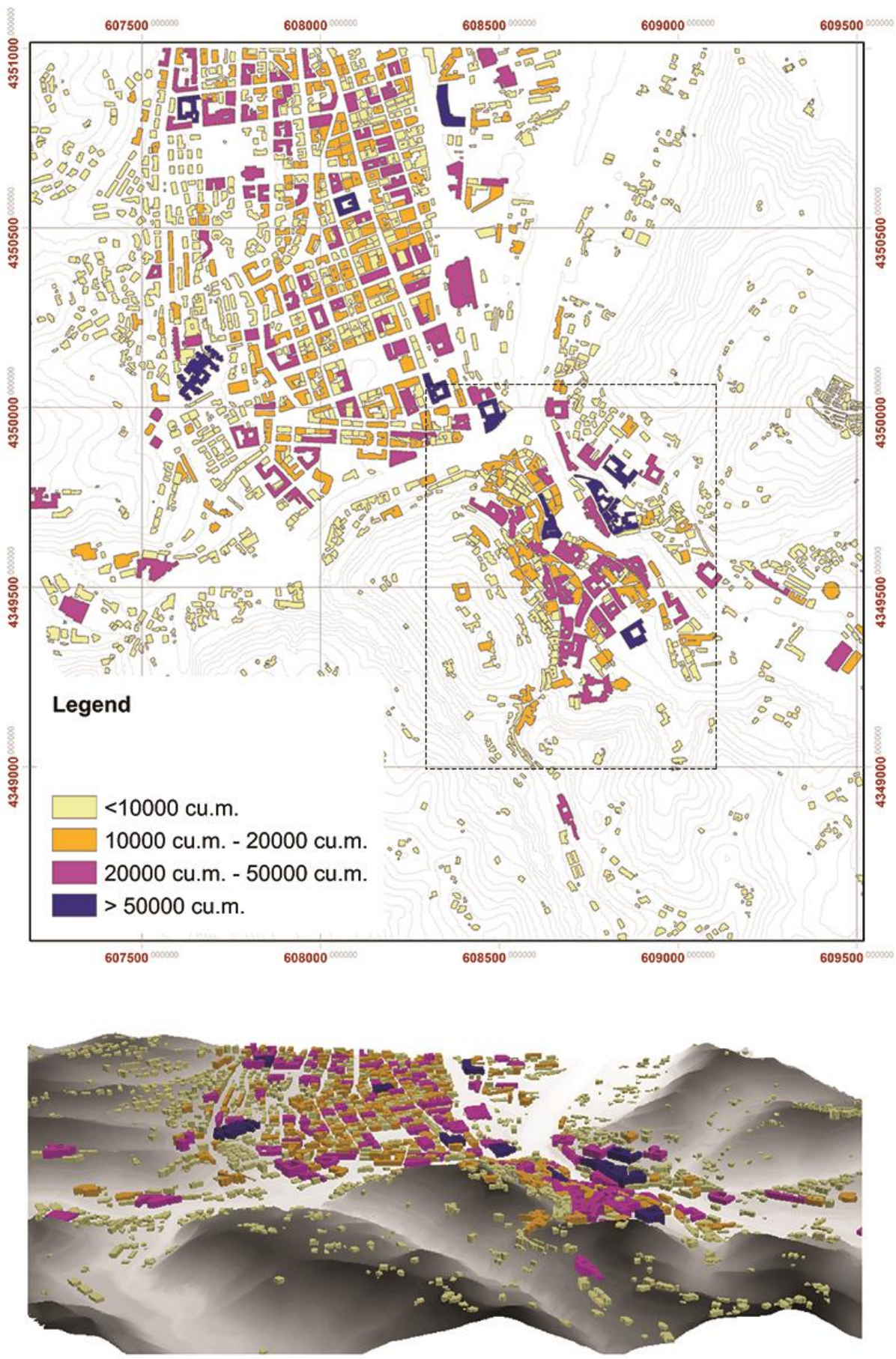
In Figure 9 the building assessment map is shown in terms of building roof typologies. Experimental results clearly show that the more recent part of the city (see the central-upper part of Figure 9) is characterized by different heterogeneous roof typologies. Conversely, the historical city centre (see dashed box in Figure 9), is mainly characterized by buildings with brick and shingles roofs together with high slopes, although some modern structures are visible. Referring to the presence of critical infrastructures, some asbestos roofs are clearly recognized and detected, which are relevant to some industrial building.

Figure 9. Classification of the buildings in the urban area of Cosenza based on the roof material : 2D map (upper panel) and 3D view (lower panel)
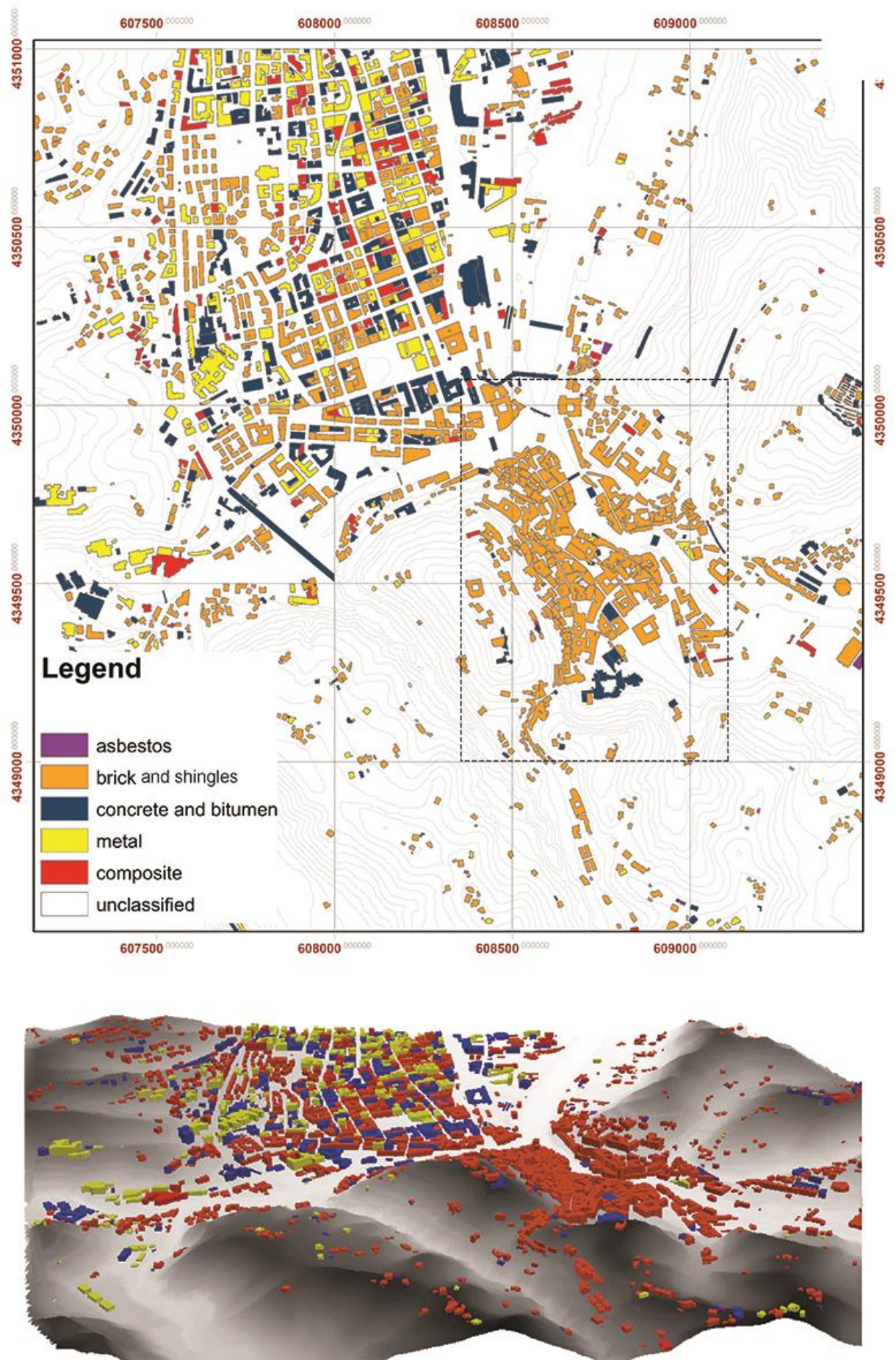
Finally, following the procedure proposed in section 3.3, a road assessment map is shown in Figure 10 in terms of the roads closing risk due to strong earthquakes for a more recent part of the city; given the small width of roads in the historical centre, the analysis would have been superfluous. The three different colours in Figure 10 are correlated to the risk of blockage due to collapse of buildings, i.e. green for low risk, yellow for moderate risk and red for high risk. Experimental results show that most of Cosenza urban roads city are characterized by high risk of blockages; only a small area in the southern part and the central sector, where is present a wide square, show a low risk of road blockage.

Figure 10. Risk map of the blockage of the roads for a selected area of Cosenza.

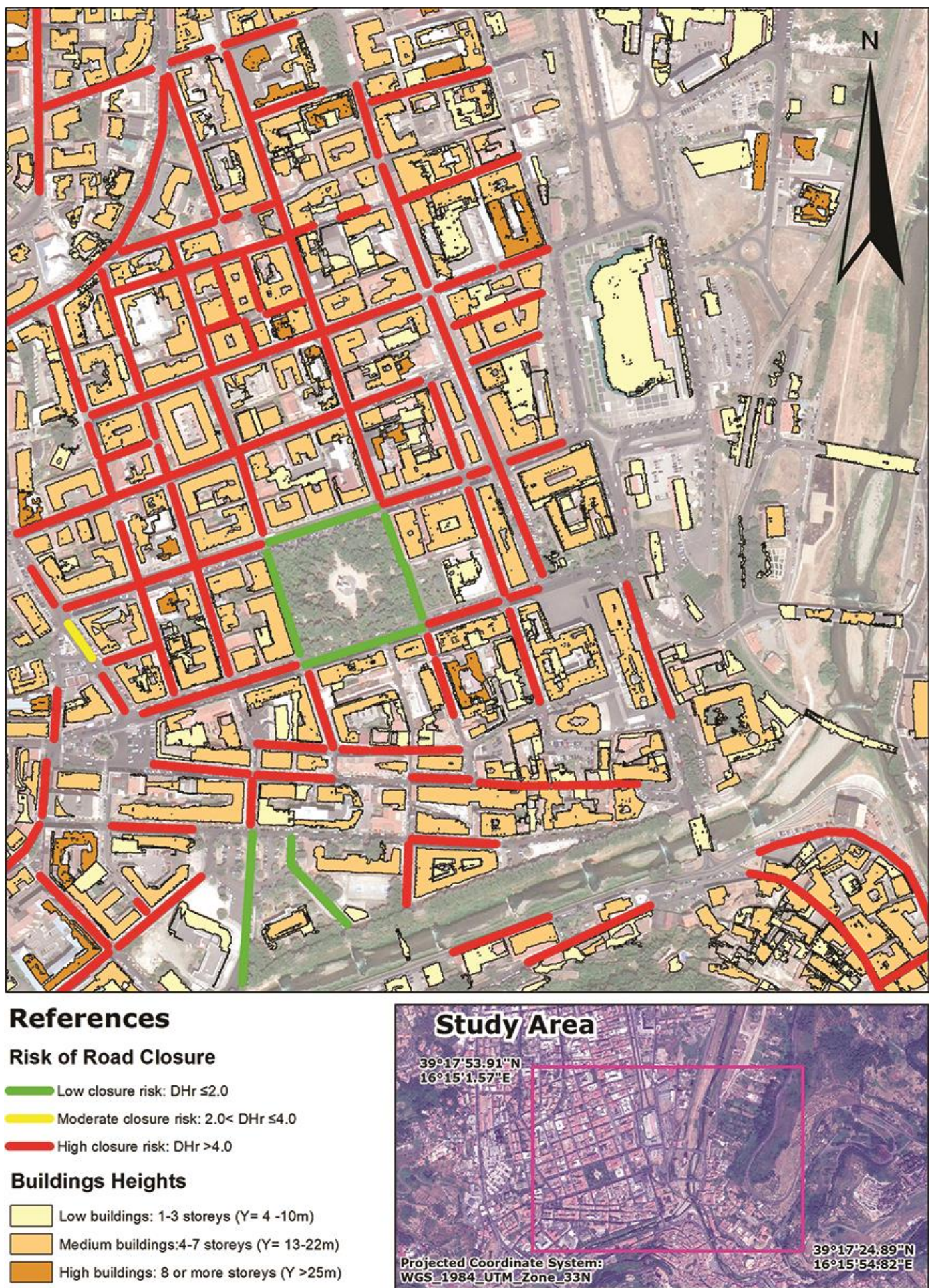


These results allow to understand that the city of Cosenza may have serious drawbacks for evacuation in case of building collapses during a strong seismic event. This pattern of closeness between multi-historic buildings and road facilities is reflected in most European cities. In order to improve the assessment of the roadblocks risk, additional information could be taken into account, such as the materials composition and the time of the building constructions.

In conclusion, all the experimental results allow demonstrating the operational benefits of the proposed approach for evaluating topographic, building and road assessment features of a seismic urbanized area. In detail, referring to the Cosenza urban environment, they show that the more recent part of the city is characterized by small heterogeneous buildings with different roof typology materials, located over flat surface morphologies with low topographic amplification values. Conversely, the historic city centre is characterized by aggregate homogeneous ancient buildings with brick roofs, located within an area with different morphological features and then susceptible to non negligible topographic amplification phenomena. In addition to the topographic and the building assessment analysis, experimental results show the high risk of road closure due to building collapses in case of destructive earthquakes for the whole urban area, thus showing high levels of both exposure and seismic vulnerability, as well as the needing of ad-hoc strategies for risk mitigation plans.

\section{Conclusions}

In this study-work, airborne remote sensing sensors and techniques have been combined and integrated within a GIS platform to provide an innovative methodology for supporting vulnerability assessment and risk mitigation plans of urban infrastructures and areas within a seismic environment. On the one hand, LiDAR measurements acquired by the airborne RIEGL LMS-Q680i sensor have been used and processed through classical signal processing techniques to provide topographic (i.e. surface height) and geometric features (i.e. building areas and heights) of urban environment and structures, respectively, in terms of DTM and DSM maps. On the other hand, airborne Hyperspectral IMSpectorV10E VNIR measurements, acquired by the IPERGEO sensor, have been used and processed through the well-known SAM-based supervised classification algorithm to provide land-use and land-cover maps of a seismic urban area, thus identifying the roof typologies of buildings, the main road facilities as well as surrounding natural environments (e.g. terrain and vegetated areas). All these remotely sensed maps have been used as intermediate products and properly integrated within a GIS platform, to obtain topographic, building and road assessment maps as value-added products supporting the vulnerability assessment and mitigation of seismic urban areas. Experimental results, gathered for the urban area of Cosenza within Calabria Region (South Italy), have demonstrated both the powerful capabilities of high-resolution airborne remotely sensed measurements and the benefits of the proposed approach for seismic vulnerability assessment purposes. In fact, the joint use of LiDAR and Hyperspectral intermediate products have provided synthetic value-added thematic maps of the observed urban environment, which can be used for evaluating and assessing the exposure level and the seismic vulnerability of urban areas in case of earthquakes, based on the analysis of co-located topographic amplification values, structural building features and road facilities. 


\section{Acknowledgments}

The present work is supported and funded by Ministero dell'Università, dell'Istruzione e della Ricerca (MIUR) under the project PON01-02710 "MASSIMO" - "Monitoraggio in Area Sismica di SIstemi MOnumentali".

\section{Author Contributions}

In this article: A.C. and A.M. wrote the manuscript and J.P.S. and M.M. attended in drafting; A.C. processed the LIDAR data and conceived the tool for topographic amplification analysis; A.M. and A.C., supported by M.S., performed the supervised analyses of the hyperspectral images; J.P.S. and M.M. conceived the procedure for the closing risk of the roads; M.M., M.F.B. and S.S. supervised the work. All authors give final approval of the version submitted.

\section{Conflicts of Interest}

The authors declare no conflict of interest.

\section{References and Notes}

1 Tucker, B.E.; Trumbull, J.G; Wyss, S.J. Some remarks concerning worldwide urban earthquake hazard and earthquake hazard mitigation. In: Tucker BE, Erdik M., Eds. Issues in urban earhquake risk. Kluwer, Dordrecht, 1994, pp 1-10.

2 White, G.F.; and Hass, J. E. Assessment of Research on Natural Hazards. Cambridge, MA: MIT Press, 1975.

3 Alexander, D. Confronting Catastrophe: New Perspectives on Natural Disasters. New York, NY, Oxford University Press, 2000.

4 Sinnott, J.D. A model for solution of ill-structured problems: Implications for everyday and abstract problem solving. In Everyday problem solving: Theory and applications, Sinnott J.D., Eds.; New York, Praeger, 1989; pp. 72-99.

5 Cutter, S.L. Vulnerability to environmental hazards. Progress in Human Geography 1996, 20, 529-539.

6 Rashed, T. and Weeks, J. Assessing vulnerability to earthquake hazards through spatial multicriteria analysis of urban areas. International Journal of Geographic Information Science 2003, 17(6), 547-576.

7 Duzgun, H.S.B.; Yucemen, M.S.; Kalaycioglu, H.S.; Celik, K.; Kemec, S.; Ertugay, K.; Deniz, A. An integrated earthquake vulnerability assessment framework for urban areas. Natural Hazards 2011, 52 (2), 917-947.

8 Davidson, R.; and Shah, H.C. A multidisciplinary urban earthquake disaster risk index. Earthquake Spectra 1997, 13(2), 211-223.

9 Borfecchia, F.; De Cecco, L.; Pollino, M.; La Porta, L.; Lugari, A.; Martini, S.; Ristoratore, E.; Pascale, C.. Active and passive remote sensing for supporting the evaluation of the urban seismic vulnerability. Italian Journal of Remote Sensing 2010, 42 (3), 129-141. 
10 Sohn, G.; Dowman, I.J. Data fusion of high-resolution satellite imagery and LiDAR data for automatic building extraction. ISPRS Journal of Photogrammetry \& Remote Sensing 2007, 62, 43-63.

11 Cova, T.J. GIS in emergency management. In Geographical Information Systems, $V$ 2: Management Issues and Applications. Longley, P.A. Eds.; John Wiley \& Sons Inc.: New York, 1999, pp. 845-858

12 Pollino, M.; Fattoruso, G.; Della Rocca, A. B.; La Porta, L.; Lo Curzio, S.; Arolchi, A.; James, V. and Pascale, C.: An Open Source GIS System for Earthquake Early Warning and Post-Event Emergency Management. In: B. Murgante, O. Gervasi, A. Iglesias, D. Taniar and B. O. Apduha (eds.) LNCS, vol. 6783, Springer Berlin-Heidelberg, 2011, pp. 376- 391.

13 Ackermann, F. Airborne Laser Scanning for Elevation Models. Geomatics Info Magazine 1996, 10, 24-25.

14 Prasad, S.; Bruce, L.M.; Chanussot, J.; Optical Remote Sensing-Advances in Signal Processing and Exploitation Techniques, Eds.; Springer-Verlag: Berlin Heidelberg, Germany, 2011, 3, pp. 344.

15 Joyce, K.E.; Belliss, S.E.; Samsonov, S.V.; McNeill, S.J.; Glassey, P.J. A review of the status of satellite remote sensing and image processing techniques for mapping natural hazards and disasters. Progress in Physical Geography 2009, 33(2), 183-207.

16 Su, G.; Qi, W.; Zhang, S.; Sim, T.; Liu, X.; Sun, R.; Sun, L.; Jin, Y.An Integrated Method Combining Remote Sensing Data and Local Knowledge for the Large-Scale Estimation of Seismic Loss Risks to Buildings in the Context of Rapid Socioeconomic Growth: A Case Study in Tangshan, China. Remote Sensing 2015, 7, 2543-2601.

17 Borengasser, M.; Hungate, W.S.; Watkins, R. Hyperspectral Remote Sensing: Principles and Applications. In Taylor \& Francis Series in Remote Sensing Applications; Qihao Weng, Series Eds.; CRC Press: Boca Raton, 2008.

18 Kruse, F.A.; Lefkoff, A.B.; Boardman, J.B.; Heidebrecht, K.B.; Shapiro, A.T.; Barloon, P.J.; Goetz, A.F.H. The Spectral Image Processing System (SIPS) - Interactive Visualization and Analysis of Imaging spectrometer Data. Remote Sensing of Environment 1993, 44, 145-163.

19 Costanzo, A.; D'Onofrio, A.; Lanzo, G.; Pagliaroli, A.; Penna, A.; Puglia, R.; Santucci De Magistris, F.; Sica, S.; Silvestri, F.; Tommasi, P. Seismic response of historical centers in Italy: selected case studies. Proceedings of 4th International Conference on Earthquake Engineering (ICEGE), workshop \#2 on "Geotechnical Earthquake Engineering related to monuments and historical centres", Thessaloniki, Greece, June 25-28, 2007.

20 Weiss, A.D. Topographic position and landforms analysis. Poster Presentation, Annual Esri International User Conference, San Diego, CA, July 9-13, 2001.

21 De Reu, J; Bourgeois, J; Bats, M; Zwertvaegher, A; Gelorini, V; De Smedt, P; Chu, W; Antrop, M; De Maeyer, P, Finke, P; Van Meirvenne, M; Verniers, J; Crombé, P. Application of the topographic position index to heterogeneous landscapes. Geomorphology 2013, 186, 39-49.

22 Gallipoli, M. R.; Mucciarelli, M.; Šket-Motnikar, B.; Zupanćić, P.;Gosar, A.; Prevolnik, S.; Herak, M.; Stipčević, J.; Herak, D.; Milutinović, Z.; Olumćeva, T. Empirical estimates of dynamic parameters on a large set of European buildings. Bulletin of Earthquake Engineering, 2010, 8, 593-607. 
(C) 2015 by the authors; licensee MDPI, Basel, Switzerland. This article is an open access article distributed under the terms and conditions of the Creative Commons Attribution license (http://creativecommons.org/licenses/by/4.0/). 